Research Article

\title{
Tensile Mechanical Properties and Failure Modes of a Basalt Fiber/Epoxy Resin Composite Material
}

\author{
Jingjing He, Junping Shi $\mathbb{D}^{\mathrm{D}}$, Xiaoshan Cao, and Yifeng Hu \\ School of Civil Engineering and Architecture, Xi'an University of Technology, Jinhua Road 48, Xi'an, Shanxi, China \\ Correspondence should be addressed to Junping Shi; shijp@xaut.edu.cn
}

Received 2 February 2018; Revised 30 March 2018; Accepted 10 April 2018; Published 3 June 2018

Academic Editor: Peng Zhang

Copyright (C) 2018 Jinging He et al. This is an open access article distributed under the Creative Commons Attribution License, which permits unrestricted use, distribution, and reproduction in any medium, provided the original work is properly cited.

\begin{abstract}
Uniaxial tensile tests of basalt fiber/epoxy (BF/EP) composite material with four different fiber orientations were conducted under four different fiber volume fractions, and the variations of $\mathrm{BF} / \mathrm{EP}$ composite material failure modes and tensile mechanical properties were analyzed. The results show that when the fiber volume fraction is constant, the tensile strength, elastic modulus, and limiting strain of $\mathrm{BF} / \mathrm{EP}$ composite material all decrease with increasing fiber orientation angle. When the fiber orientation angle is constant, the tensile strength, elastic modulus, and limiting strain of $\mathrm{BF} / \mathrm{EP}$ composite material all increase with increasing fiber volume fraction. A certain degree of fiber clustering appears in the epoxy resin when the basalt fiber volume fraction is $>1.2 \%$. The fiber equidistribution coefficient and clustering fiber content were used to characterize the basalt fiber clustering effect. With the increase of fiber volume fraction, the clustering fiber content gradually increased, but the fiber equidistribution coefficient decreased. Meanwhile, based on Tsai theory, a geometric model and a tensile mechanical model of the clustering fiber are established. By considering the fiber clustering effect, the BF/EP composite material tensile strength is calculated, and the calculated values are close to the experimental results.
\end{abstract}

\section{Introduction}

Basalt fiber is a new type of mineral fiber made from the melting of natural basalt at high temperature $\left(1400-1500^{\circ} \mathrm{C}\right)$ [1]. Because of its characteristics such as high elastic modulus and tensile strength, it is widely applied in industries such as machine building, aviation, and building materials [2-5]. Basalt fiber/epoxy (BF/EP) composite material is made by adding specific amounts (volume fractions) of basalt fiber to epoxy resin. The addition of basalt fiber effectively reduces the internal stress of the epoxy resin (matrix) and improves its mechanical properties [6].

Because of the high tensile strength, light weight, and convenient construction, $\mathrm{BF} / \mathrm{EP}$ composite material can be used as a new type of reinforcement material and applied to repair and strengthening of concrete structure and steel structure in civil engineering [7]. For example, the reinforcement material is glued to the tensile area of concrete component (walls, beams, slabs, and columns), which can effectively improve its carrying capacity, avoid excessive deformation of the cross section, and prevent the crack expansion [8-10]. And in the shear area of the concrete beam, reinforced material can effectively improve its shearing capacity $[11,12]$. By gluing the reinforcement material to the intersection of beam and column, the limiting strain of the plastic-hinge zone can be constrained, and the seismic behavior of concrete structure and steel structure can be improved [13, 14]. Meanwhile, compared with glass fiber/epoxy (GF/EP) composite material and carbon fiber/epoxy (CF/EP) composite material, due to its excellent properties such as higher corrosion resistance, excellent durability, and resistance to high temperature, BF/EP composite material can be used for strengthening the structure (concrete and steel) after long-term chemical corrosion or exposure to fire so that the service life of the structure is improved. Related research shows that reinforced component (concrete and steel) has higher fatigue resist [15]. Therefore, $\mathrm{BF} / \mathrm{EP}$ composite material can also be used to strengthen the bridge structure and dam body under long-term action of fatigue load.

To sum up, the intensive research of the manufacturing process and mechanical property of $\mathrm{BF} / \mathrm{EP}$ composite 
Table 1: Physical and mechanical indexes of basalt fiber.

\begin{tabular}{lccccc}
\hline Density $\left(\mathrm{g} / \mathrm{cm}^{3}\right)$ & Tensile strength $(\mathrm{MPa})$ & Limit elongation $(\%)$ & Tensile modulus $(\mathrm{GPa})$ & Diameter $(\mathrm{mm})$ & Length $(\mathrm{mm})$ \\
\hline 2.65 & 3300 & 3.2 & 100 & 0.01 & 12 \\
\hline
\end{tabular}

material provides powerful help for its application in civil engineering. At present, research on $\mathrm{BF} / \mathrm{EP}$ composite material focuses on the influence of fiber surface modification on mechanical properties $[16,17]$, yet there is some research on the influence of fiber distribution on tensile properties of $\mathrm{BF} / \mathrm{EP}$ composite material. However, the fiber distribution can also have a significant influence on mechanical properties of the $\mathrm{BF} / \mathrm{EP}$ composite material [18-20]. As the main parameter reflects the fiber within the matrix, fiber orientation is an important factor influencing the mechanical properties of $\mathrm{BF} / \mathrm{EP}$ composite material [21, 22]. Therefore, some scholars have made attempts to use flow-field orientation (imposed by an internal fluid viscous force) before matrix curing to control fiber orientation. For example, Yang et al. [23] conducted research on the flow field formed in the interval between two concentric rotating cylinders and the fiber movement and orientation in the flow field. Their results show that fibers moved and oriented along the flow field. With the use of a numerical algorithm employing the finite volume and finite difference methods, Zhang and Jie [24] analyzed the flowing behavior of a fiber-reinforced polymer melt in a contraction flow chamber. The results show that when shearing motion dominates, fibers orient in cyclonic rotation, whereas when stretching dominates, fibers exhibit monopodium stretching.

In this paper, with the use of a handmade chute device, 16 kinds of $\mathrm{BF} / \mathrm{EP}$ composite materials (with different volume fractions and different fiber orientations) were produced. Uniaxial tensile testing of these $\mathrm{BF} / \mathrm{EP}$ composite materials was then conducted. The goal is to understand the influence of fiber orientation and fiber volume fraction on the tensile properties of the $\mathrm{BF} / \mathrm{EP}$ composite material and to provide some experimental bases for the design and engineering application of $\mathrm{BF} / \mathrm{EP}$ composite material.

\section{Experiments and Research on Tensile Properties of BF/EP Composite Material}

2.1. Material Parameters and Raw Materials. The curing agent used was polyamide, and the diluent was acetone. The matrix was compounded according to a mass ratio of $M_{1}$ (epoxy resin) $: M_{2}$ (curing agent) $: M_{3}$ (diluent) $=38: 25: 1$. As tested after solidification, the matrix had a tensile strength of $16.67 \mathrm{MPa}$, a limiting strain of 0.002 , a shear strength of $21.73 \mathrm{MPa}$, and a curing residual stress of $0.31 \mathrm{MPa}$. The fiber employed was a chopped discontinuous basalt fiber, and the physical and mechanical indexes of which are listed in Table 1.

2.2. Design and Technology of BF/EP Composite Material. First, we designed the basic parameters of the BF/EP composite material. The volume fractions $V_{\mathrm{f}}$ of basalt fiber tested are $0.6 \%, 0.9 \%, 1.2 \%$, and $1.5 \%$. The orientation angles $\theta$ of fibers in the matrix are $0^{\circ}, 15^{\circ}, 30^{\circ}$, and $45^{\circ}$. The

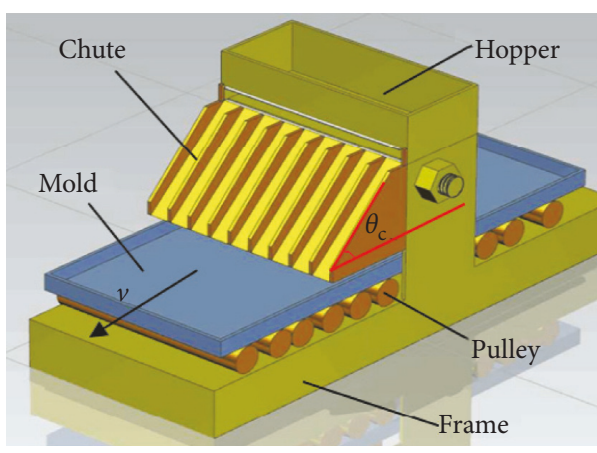

FIgURE 1: The chute stretch device.

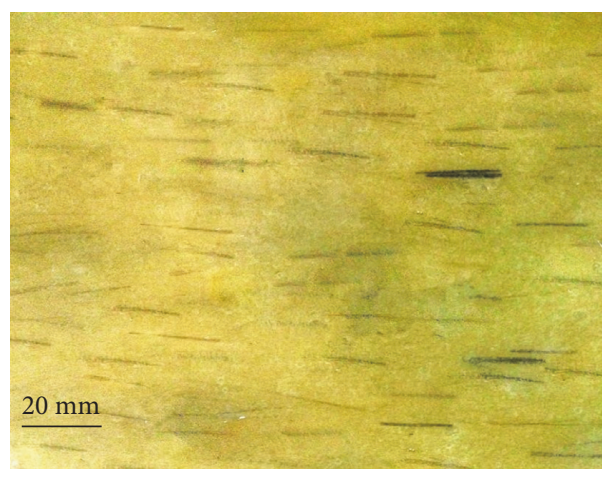

FIgURE 2: Molding effect of oriented basalt fiber/epoxy composite material $\left(V_{\mathrm{f}}=0.9 \%\right)$.

size of each sample is $10 \mathrm{~mm} \times 20 \mathrm{~mm} \times 300 \mathrm{~mm}$, and three samples comprised one group.

Second, we used a handmade device to fabricate the oriented basalt fiber/epoxy composite material. For the epoxy resin, a curing agent and diluent were mixed according to a predetermined proportion, thus forming a liquid epoxy resin matrix. Basalt fiber was then added, and the mixture was stirred for two minutes. The resulting mixture was then poured into the hopper of the chute stretch device (Figure 1). The mixture flowed down the chute into the mold under the influence of gravity, forming an elongation flow field in the matrix that led to fiber orientation approaching the elongation flow-field direction $[25,26]$. By controlling the angle between the chute and the surface, different gravity flow fields were formed. Chute angles $\theta_{c}$ of $15^{\circ}, 23^{\circ}, 30^{\circ}$, and $45^{\circ}$ produced oriented basalt fiber/epoxy composite materials with fiber volume fractions of $0.6 \%, 0.9 \%, 1.2 \%$, and $1.5 \%$, respectively. For example, Figure 2 shows an oriented basalt fiber/epoxy composite material $\left(V_{\mathrm{f}}=0.9 \%\right)$.

Third, we fabricated BF/EP composite materials with different fiber orientations. After the completion of matrix solidification (about $48 \mathrm{~h}$ at $20^{\circ} \mathrm{C} \pm 2^{\circ} \mathrm{C}$ ), along the fiber direction, we cut the samples at included angles of $0^{\circ}, 15^{\circ}, 30^{\circ}$, 
and $45^{\circ}$, thus obtaining $\mathrm{BF} / \mathrm{EP}$ composite material with four different fiber orientations.

2.3. Analysis of the Experimental Results. Uniaxial tensile tests were conducted using a WAW-1000 universal testing machine and stress-strain curves were collected at a loading rate of $5 \mathrm{~N} / \mathrm{s}$. Figure 3 shows the tensile test machine (WAW-1000).

Figure 3 shows the tensile test device. The tensile stressstrain curves of different kinds of BF/EP composite materials (with different fiber orientations and different fiber volume fractions) are given in Figures 4(a)-4(d). According to Figure $4(\mathrm{a})$, when $V_{\mathrm{f}}$ was $0.6 \%$ and $\theta$ was $0^{\circ}, 15^{\circ}$, and $30^{\circ}$, compared with the epoxy resin matrix, the tensile strength of $\mathrm{BF} / \mathrm{EP}$ composite material increased by $16 \%, 8 \%$, and $1 \%$, respectively, and the limiting strain increased by $22 \%, 5 \%$, and $1 \%$, respectively. According to Figure $4(\mathrm{~b})$, when $V_{\mathrm{f}}$ was $0.9 \%$ and $\theta$ was $0^{\circ}, 15^{\circ}, 30^{\circ}$, and $45^{\circ}$, compared with the epoxy resin matrix, the tensile strength of BF/EP composite material increased by $45 \%, 36 \%, 22 \%$, and $12 \%$, respectively, and the limiting strain increased by $29 \%, 22 \%, 8 \%$, and $4 \%$, respectively. According to Figure 4(c), when $V_{\mathrm{f}}$ was $1.2 \%$ and $\theta$ was $0^{\circ}, 15^{\circ}, 30^{\circ}$, and $45^{\circ}$, compared with the epoxy resin matrix, the tensile strength of $\mathrm{BF} / \mathrm{EP}$ composite material increased by $90 \%, 81 \%, 56 \%$, and $34 \%$, respectively, and the limiting strain increased by $88 \%, 54 \%, 35 \%$, and $20 \%$, respectively. According to Figure $4(\mathrm{~d})$, when $V_{\mathrm{f}}$ was $1.5 \%$ and $\theta$ was $0^{\circ}, 15^{\circ}, 30^{\circ}$, and $45^{\circ}$, compared with the epoxy resin matrix, the tensile strength of $\mathrm{BF} / \mathrm{EP}$ composite material increased by $106 \%, 98 \%, 80 \%$, and $58 \%$, respectively, and the limiting strain increased by $114 \%, 75 \%, 38 \%$, and $21 \%$, respectively. Table 2 lists the tensile strengths and limiting strains of the BF/EP composite materials. One can see that the addition of basalt fiber has different impacts on improving the tensile strength and limiting strain of the matrix. When the fiber volume fraction is constant, the tensile strength and limiting strain of BF/EP composite material both decrease with increasing fiber orientation angle. When the fiber orientation angle is constant, the tensile strength and limiting strain of $\mathrm{BF} / \mathrm{EP}$ composite material both increase with increasing fiber volume fraction.

The elastic modulus of the matrix and $\mathrm{BF} / \mathrm{EP}$ composite material can be obtained by calculating the slope of the elastic section of the stress-strain curve (Figures 4(a)-4(d)). The calculation results are given in Table 2. It can be seen from Table 2 that when the fiber volume fraction is constant, the elastic modulus of $\mathrm{BF} / \mathrm{EP}$ composite material decreases with increasing fiber orientation angle. For example, when $V_{\mathrm{f}}$ was $0.6 \%$ and $\theta$ was $0^{\circ}, 15^{\circ}, 30^{\circ}$, and $45^{\circ}$, compared with the epoxy resin matrix, the elastic modulus of BF/EP composite material increased by 59\%, 34\%, 27\%, and $13 \%$, respectively. When the fiber volume fractions were $0.9 \%, 1.2 \%$, and $1.5 \%$, the trends in the elastic modulus of $\mathrm{BF} / \mathrm{EP}$ composite material were similar to that with a fiber volume fraction of $0.6 \%$.

It can also be seen from Table 2 that when the fiber orientation angle is constant, the elastic modulus of $\mathrm{BF} / \mathrm{EP}$ composite material increases with increasing fiber volume fraction. For example, when $\theta$ was $0^{\circ}$ and $V_{\mathrm{f}}$ was $0.6 \%, 0.9 \%$,

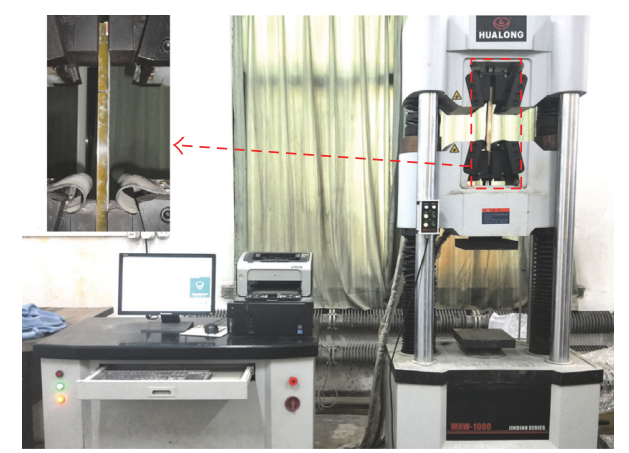

Figure 3: The tensile test machine (WAW-1000).

$1.2 \%$, and $1.5 \%$, compared with the epoxy resin matrix, the elastic modulus of $\mathrm{BF} / \mathrm{EP}$ composite material increased by $59 \%, 71 \%, 93 \%$, and $124 \%$, respectively. When the fiber orientation angles were $15^{\circ}, 30^{\circ}$, and $45^{\circ}$, the trends of the elastic modulus of $\mathrm{BF} / \mathrm{EP}$ composite material were similar to that with a fiber orientation angle of $0^{\circ}$.

In conclusion, the tensile strength, limiting strain, and elastic modulus of the BF/EP composite material are related to the orientation and volume fraction of fiber. To further analyze the influence of the orientation and volume fraction of fiber on tensile properties of the BF/EP composite material, the following enhancement coefficient $\beta$ is introduced:

$$
\beta=\frac{I_{\mathrm{f}}}{I_{\mathrm{m}}},
$$

where $I_{\mathrm{f}}$ is the tensile property indicator of the BF/EP composite material, such as its tensile strength $\sigma_{\mathrm{f}}$, elastic modulus $E_{\mathrm{f}}$, and limiting strain $\varepsilon_{\mathrm{f}}$, and $I_{\mathrm{m}}$ is the tensile property indicator of the matrix, such as its tensile strength $\sigma_{\mathrm{m}}$, elastic modulus $E_{\mathrm{m}}$, and limiting strain $\varepsilon_{\mathrm{m}}$. Therefore, the enhancement coefficient of tensile strength $\left(\beta_{\mathrm{t}}\right)$, the enhancement coefficient of elastic modulus $\left(\beta_{\mathrm{e}}\right)$, and the enhancement coefficient of limiting strain $\left(\beta_{\mathrm{s}}\right)$, for different orientations and volume fractions, can be obtained from Table 2. We used the linear regression method to analyze the change in the enhancement coefficient with fiber orientation angle and fiber volume fraction. The fitting surface functions are

$$
\begin{aligned}
\beta_{\mathrm{s}}= & 1.274-0.3661 i-0.008179 \theta+0.4552 i^{2} \\
& -0.00007442 i \theta+0.00004652 \theta^{2}, \\
\beta_{\mathrm{e}}= & 1.469+0.05436 i-0.008847 \theta+0.2491 i^{2} \\
& -0.01271 i \theta+0.000182 \theta^{2}, \\
\beta_{\mathrm{t}}= & 0.3937+1.301 i+0.003205 \theta-0.08973 i^{2} \\
& -0.008662 i \theta-0.00006437 \theta^{2} .
\end{aligned}
$$

The correlation coefficients for (2)-(4) are 0.9677, 0.9783 , and 0.9791 , respectively. These experiment results provide useful guidance for the design and manufacture of BF/EP composite material [27] Figure 5. 


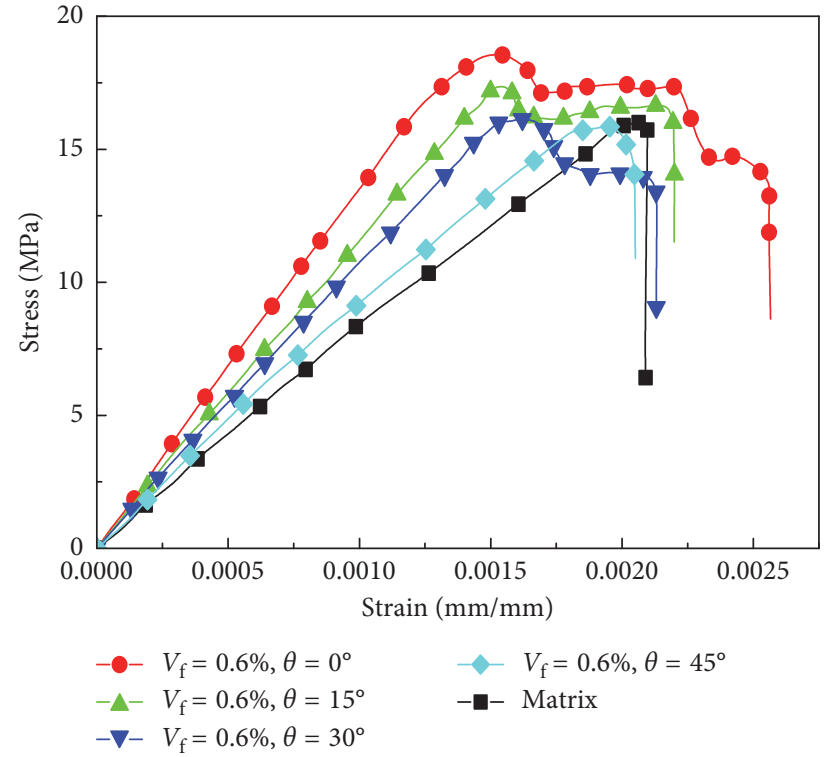

(a)

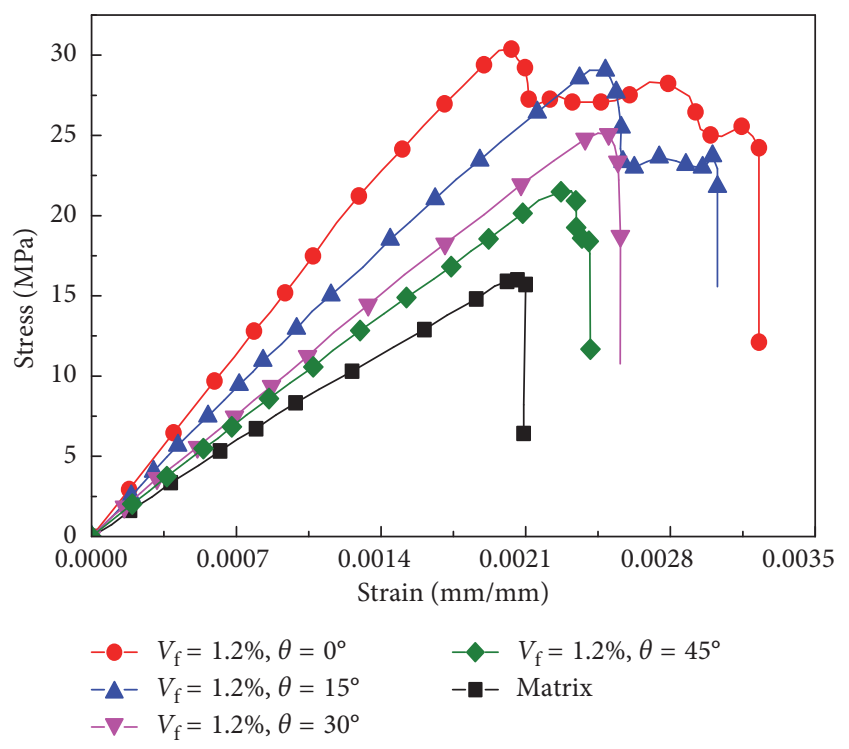

(c)

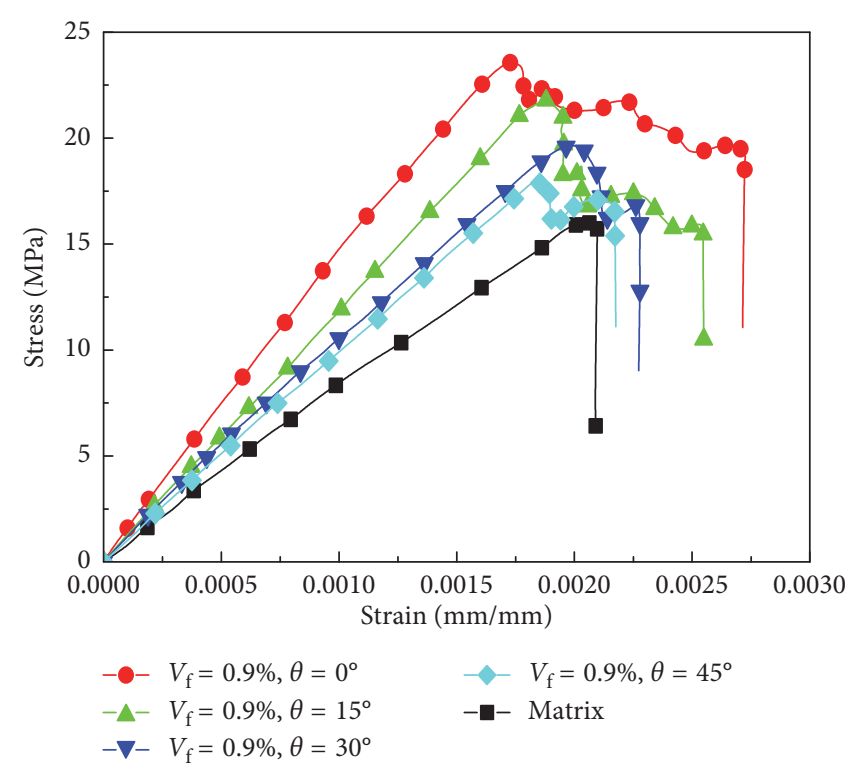

(b)

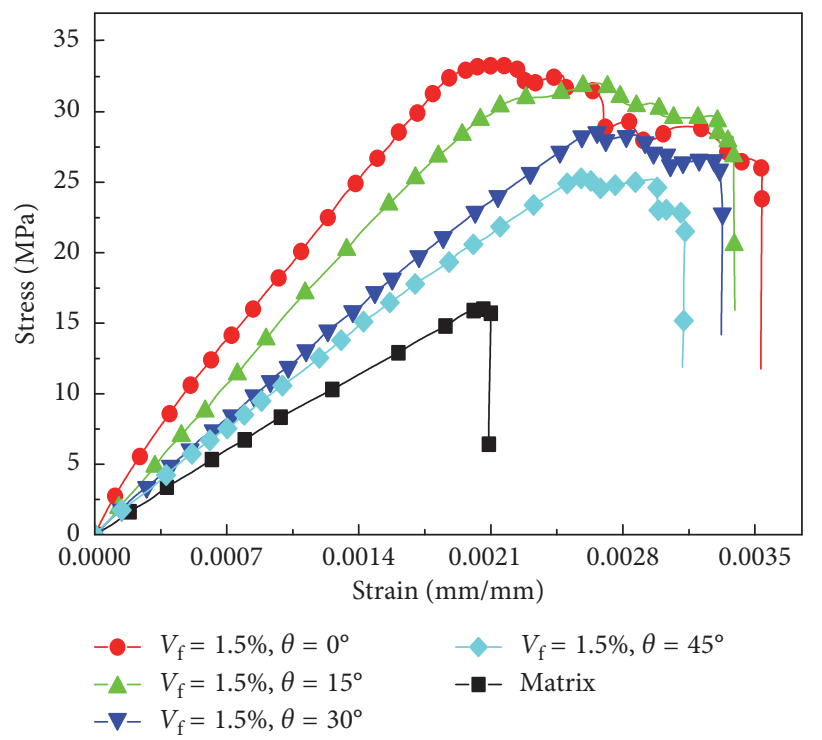

(d)

Figure 4: Tensile stress-strain curves of BF/EP composite materials with different orientations and different volume fractions of fibers.

\section{Analysis of the BF/EP Composite Material's Tensile Failure Mode}

We analyzed the tensile failure mode of samples by observing the fracture surface of samples through scanning electron microscopy. It was found that there is a certain degree of agglomeration occurring in the epoxy resin when the basalt fiber volume fraction is $>1.2 \%$. Figure 5 shows images of the $\mathrm{BF} / \mathrm{EP}$ composite material sample fracture surface. Figures 5(a) and 5(b) show agglomeration of fibers in the fracture surface when fiber volume fractions were $1.2 \%$ and $1.5 \%$. This agglomeration occurs because the fibers and matrix undergo different mixing mechanisms, making it difficult for the fibers to distribute evenly within the epoxy resin. Consequently, some fibers are present in groups or bundles [20].

This kind of fiber agglomeration can be called "fiber clustering." Because of the fiber clustering effect, there are only small gaps in between fibers, which make it hard for the matrix to enter the fiber agglomerates, and there are crevices in the fiber agglomerates (Figure 5(c)). Fibers in fiber agglomerates are loosely bound to the matrix, and its most common tensile failure mode presents as fiber pulling out, whereas peripheral fibers of the fiber agglomerates are well bound to the matrix, with its most common tensile failure mode presenting as fiber pulling off (Figure 5). According to Tsai theory $[28,29]$, when the matrix cracks because the tensile force exceeds its tensile strength, all its load is 
TABLE 2: Tensile property parameters of BF/EP composite material.

\begin{tabular}{|c|c|c|c|c|c|}
\hline Sample number & $\begin{array}{l}\text { Fiber orientation } \\
\text { angle, } \theta\left(^{\circ}\right)\end{array}$ & $\begin{array}{l}\text { Fiber volume } \\
\text { fraction (\%) }\end{array}$ & $\begin{array}{c}\text { Tensile strength } \\
(\mathrm{MPa})\end{array}$ & $\begin{array}{l}\text { Limiting strain } \\
(\mathrm{mm} / \mathrm{mm})\end{array}$ & $\begin{array}{c}\text { Elastic modulus } \\
(\mathrm{MPa})\end{array}$ \\
\hline $0-0$ & 0 & 0 & 16.13 & 0.00210 & 8576 \\
\hline $1-1$ & 0 & 0.6 & 18.54 & 0.00257 & 13638 \\
\hline $1-2$ & 15 & 0.6 & 17.35 & 0.00220 & 11530 \\
\hline $1-3$ & 30 & 0.6 & 16.12 & 0.00213 & 10918 \\
\hline $1-4$ & 45 & 0.6 & 15.85 & 0.00205 & 9730 \\
\hline $2-1$ & 0 & 0.9 & 23.56 & 0.00273 & 14741 \\
\hline $2-2$ & 15 & 0.9 & 21.78 & 0.00255 & 11868 \\
\hline $2-3$ & 30 & 0.9 & 19.62 & 0.00228 & 11257 \\
\hline $2-4$ & 45 & 0.9 & 17.90 & 0.00218 & 10315 \\
\hline $3-1$ & 0 & 1.2 & 30.37 & 0.00323 & 16568 \\
\hline $3-2$ & 15 & 1.2 & 29.05 & 0.00303 & 13320 \\
\hline $3-3$ & 30 & 1.2 & 25.13 & 0.00256 & 11360 \\
\hline $3-4$ & 45 & 1.2 & 21.54 & 0.00241 & 10428 \\
\hline $4-1$ & 0 & 1.5 & 33.26 & 0.00354 & 19226 \\
\hline $4-2$ & 15 & 1.5 & 32.01 & 0.00339 & 15302 \\
\hline $4-3$ & 30 & 1.5 & 28.60 & 0.00333 & 11675 \\
\hline $4-4$ & 45 & 1.5 & 25.27 & 0.00313 & 10911 \\
\hline
\end{tabular}
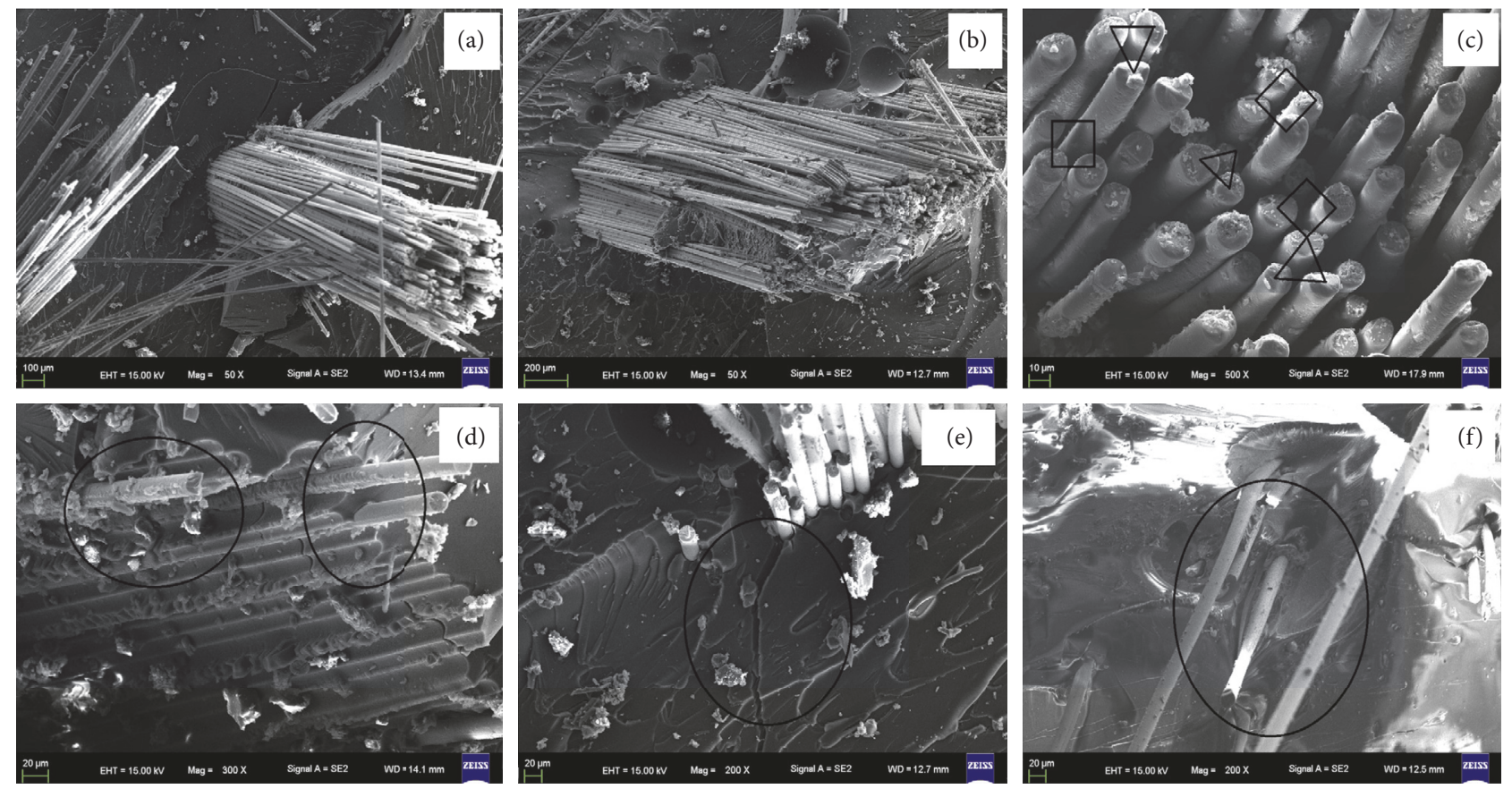

FIgURE 5: E-sports scan results of the BF/EP composite material sample fracture surface.

transferred to the fiber for its pull off. The fiber approaches its yield strength and is broken with the matrix. Thus, the bonding strength of the fiber and matrix is greater than the yield strength of the fiber, and meanwhile, the bonding strength of the fiber and matrix is greater than the tensile strength of the matrix alone. Therefore, the fibers play an enhanced role in the matrix.

However, the matrix is destroyed before the pullout fiber reaches its yield limit, and the bonding strength of the fiber and matrix is smaller than the tensile strength of the fiber, so the fibers do not play an enhanced role in the matrix. Similarly, a crevice in a fiber cluster leads to matrix cracking in advance to some degree, and the tensile strength of the composite decreases (Figure 5(e)). Compared with the sample fracture surface of a fiber cluster, the fracture surface of samples is rougher and has large bumps when the fiber has an even distribution (Figure 5(f)). These bumps occur because when the fibers are evenly distributed, they bond well with the matrix, diminishing the stress concentration within the matrix and changing the matrix cracking stress path, thus leading to greater roughness of the fracture surface. The reason is that the tensile strength of a solid material decreases with the increase of the three-dimensional roughness of its fracture surface [30,31]. In conclusion, fiber clustering 


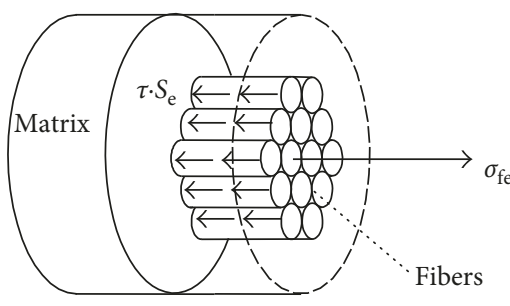

(a)

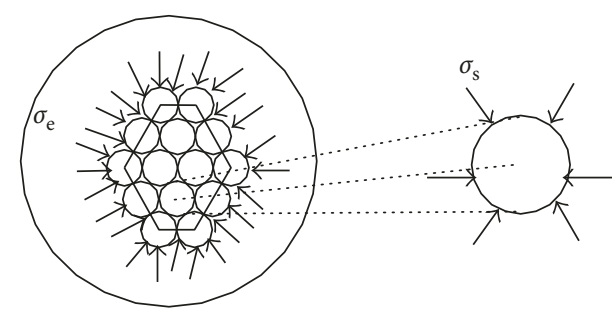

(b)

FIGURE 6: Micromechanics model of cluster-fiber-reinforced epoxy matrix composites.

has reduced the utilization of fibers to some degree and diminished the improvement in tensile strength of the matrix. Consequently, in the design and engineering application of $\mathrm{BF} / \mathrm{EP}$ composite material, attempts should be made to decrease or avoid fiber clustering.

\section{Performance and Mechanism Analysis of Stretchability of Fiber-Reinforced Epoxy Matrix Composites}

4.1. Characterization of Fiber Clustering Effect. Consider an agglomerate of oriented fibers and matrix material in their adjacent area as a mesocharacteristic unit, as shown in Figure 6.

Figure 6(a) shows the stress produced by the bonding between clustering fibers and matrix material, and Figure 6 (b) shows the confining stress generated by matrix solidification contraction on fiber agglomerates. Therefore, the stress acting on fiber agglomerates in the matrix material is

$$
\begin{aligned}
\sigma_{\mathrm{fe}}= & \tau \cdot S_{\mathrm{e}}+\int_{0}^{N} \mu \cdot \sigma_{\mathrm{s}} d N=\tau \cdot\left[C \cdot l_{\mathrm{f}}+N \pi\left(\frac{d_{\mathrm{f}}}{2}\right)^{2}\right] \\
& +\mu \cdot \sigma_{\mathrm{e}} \cdot C \cdot l_{\mathrm{f}},
\end{aligned}
$$

where $\sigma_{\mathrm{fe}}$ is the stress acting on clustering fibers in the matrix materials; $\tau$ is the strength of bonding between fibers and matrix material; $S_{e}$ is the bonding surface area between the clustering fiber (the number of fibers is $N$ ) and the epoxy; $\mu$ is the friction coefficient between fibers; $C$ is the perimeter of fiber agglomerates section; $d_{\mathrm{f}}$ and $l_{\mathrm{f}}$ are, respectively, the diameter and length of a fiber; $\sigma_{\mathrm{s}}$ is the average confining stress of a single fiber inside the fiber agglomerate; and $\sigma_{\mathrm{e}}$ is the confining stress of fiber agglomerates (the numerical value of which is equal to the residual stress generated by matrix solidification contraction). Therefore, the stress acting on the clustering fibers in the matrix material can be divided into a bonding force between fibers and matrix material and friction between fibers. However, the stress acting on the uniformly distributed fibers in the matrix material is the bonding force between fibers and matrix material. Based on this, without considering the fiber tip area, the fiber equidistribution coefficient $\eta_{\mathrm{e}}$ is introduced to represent the influence of clustering of fibers on tensile strength of the complex; that is,

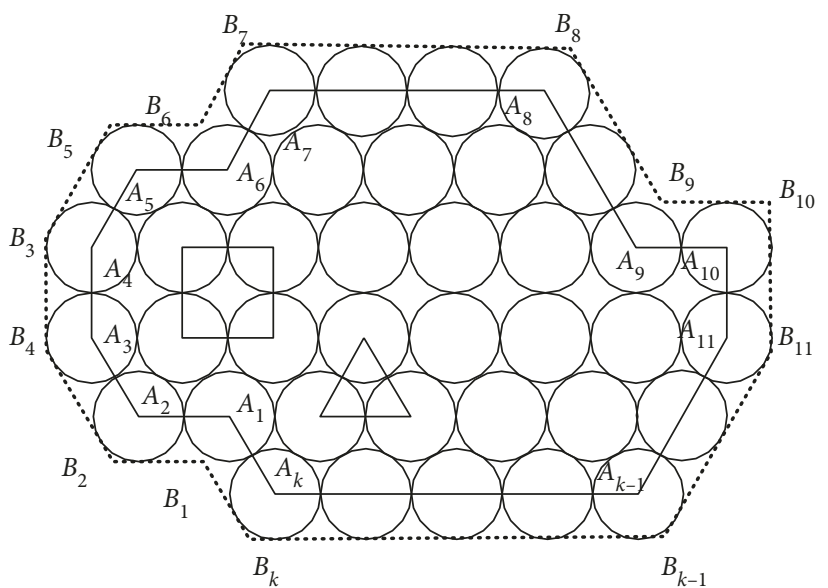

Figure 7: $k$-sided polygon fiber-clustering model.

$$
\eta_{\mathrm{e}}=\frac{\sigma_{\mathrm{fe}}}{\sigma_{\mathrm{f}}}=\frac{\tau \cdot S_{\mathrm{e}}+\int_{0}^{N} \mu \cdot \sigma_{\mathrm{s}} d N}{\tau \cdot S_{\mathrm{f}}}=\frac{\tau \cdot C \cdot l_{\mathrm{f}}+\mu \cdot \sigma_{\mathrm{e}} \cdot C \cdot l_{\mathrm{f}}}{\tau \cdot N \cdot 2 \pi d_{\mathrm{f}} l_{\mathrm{f}}}
$$

where $\sigma_{\mathrm{f}}$ is the stress of $N$ uniformly distributed fibers in the matrix material and $S_{\mathrm{f}}$ is the bond area of $N$ uniformly distributed fibers and matrix material. For the analysis of the geometric characteristics of fiber agglomerates, we assume that there are agglomerates of fibers (containing $N$ fibers) in the matrix material and that the arrangement of fibers in the fiber agglomerates includes a triangular arrangement and a square arrangement (as shown in Figure 5(c)), from the fiber center in the periphery of fiber agglomerates, randomly forming a polygon with $k$ sides, that is, $A_{1}, A_{2}, A_{3}, \ldots, A_{k}$, as shown in Figure 7, which is called the " $k$-sided polygon fiber-clustering model."

If $\alpha_{1}, \alpha_{2}, \alpha_{3}, \ldots, \alpha_{k}$ are the interior angles of $k$-sided polygon $A_{1}, A_{2}, A_{3}, \ldots, A_{k}, M$ is the number of the most peripheral fibers of the clustering fibers and $c$ is the perimeter of $k$-sided polygon $A_{1}, A_{2}, A_{3}, \ldots, A_{k}$, and then, the relationship between $C$ and $c$ can be deduced according to the geometrical relationship:

$$
\begin{aligned}
& M=\frac{c}{d_{\mathrm{f}}}, \\
& \eta_{\mathrm{f}}=1-\frac{l_{\mathrm{f}(\text { crit })}}{2 l_{\mathrm{f}}},
\end{aligned}
$$




$$
\begin{aligned}
C= & \pi d_{\mathrm{f}} \cdot(M-k) \\
& +\left[2 \pi d_{\mathrm{f}} \cdot \frac{2 \pi-\alpha_{1}}{2 \pi}+2 \pi d_{\mathrm{f}} \cdot \frac{2 \pi-\alpha_{2}}{2 \pi}+\cdots+2 \pi d_{\mathrm{f}} \cdot \frac{2 \pi-\alpha_{k}}{2 \pi}\right] .
\end{aligned}
$$

Equation (9) can be simplified to

$$
C=\pi d_{\mathrm{f}} \cdot(M-k)+d_{\mathrm{f}} \cdot\left[2 k \pi-\left(\alpha_{1}+\alpha_{2}+\cdots+\alpha_{k}\right)\right] \text {. }
$$

Substituting (7) and (8) into (10) gives

$$
C=c \cdot \pi+2 \pi d_{\mathrm{f}} \text {. }
$$

All edges of $k$-sided polygon $A_{1}, A_{2}, A_{3}, \ldots, A_{k}$ are offset outward by $d_{\mathrm{f}} / 2$ to form $k$-sided polygon $B_{1}, B_{2}, B_{3}, \ldots, B_{k}$, where $S$ is the area of $k$-sided polygon $B_{1}, B_{2}, B_{3}, \ldots, B_{k}$. Therefore,

$S \approx n_{1} \cdot d_{\mathrm{f}}^{2}$ (square arrangement of fibers),

$$
S \approx n_{2} \cdot \frac{3 \sqrt{3}}{4} d_{\mathrm{f}}^{2} \text { (triangular arrangement of fibers), }
$$

where $n_{1}$ and $n_{2}$ are, respectively, the number of fibers inside the fiber agglomerates in square and triangular arrangements. It is considered that the fibers inside the fiber agglomerates are in square and triangular arrangements; therefore, the range of the number $N$ of fibers in the fiber agglomerates can be determined to be $n_{1}$ to $n_{2}$. By taking $N=0.5\left(n_{1}+n_{2}\right)$ and the sectional area of fiber agglomerates approximate to the area of $k$ polygon $B_{1}, B_{2}, B_{3}, \ldots, B_{k}$, when the fibers cluster in a randomly formed $k$-sided polygon, the equidistribution coefficient is

$$
\eta_{\mathrm{e}}=\frac{6 \sqrt{3}}{4+3 \sqrt{3}} \cdot \frac{d_{\mathrm{f}}^{2}}{S} \cdot\left(\frac{c}{2 d_{\mathrm{f}}}+\frac{\mu \cdot \sigma_{\mathrm{e}} \cdot c}{2 \tau \cdot d_{\mathrm{f}}}+\frac{\mu \cdot \sigma_{\mathrm{e}}}{\tau}+1\right) .
$$

4.2. Analysis of BF/EP Composite Material Tensile Property with Fiber Clustering. Based on Tsai theory [28, 29], if we take the BF/EP composite as a fiber-reinforced multiple complex, then the tensile strength of the complex is the elastic superposition of the tensile strength of fibers and matrix material:

$$
\sigma_{\mathrm{fc}}=\sigma_{\mathrm{f}} V_{\mathrm{f}}+\sigma_{\mathrm{m}} V_{\mathrm{m}}=\sigma_{\mathrm{m}}\left[1+(n-1) V_{\mathrm{f}}\right],
$$

where $\sigma_{\mathrm{fc}}$ is the stress of the complex at the elastic stage; $\sigma_{\mathrm{m}}$ is the stress of the matrix material; $\sigma_{\mathrm{f}}$ is the stress acting on the fibers; $V_{\mathrm{m}}$ and $V_{\mathrm{f}}$ are, respectively, the volume fraction of matrix material and the volume fraction of fibers; $n=E_{\mathrm{m}} / E_{\mathrm{f}}$; $V_{\mathrm{m}}+V_{\mathrm{f}}=1 ; E_{\mathrm{m}}$ is the elasticity modulus of the epoxy matrix; and $E_{\mathrm{f}}$ is the elasticity modulus of the fibers. If we assume that the matrix material crack after its tensile strength is reached under a tensile force, then all loads are transferred to the fibers until they are broken, and thus,

$$
\sigma_{\mathrm{fc}}^{\mathrm{u}}=\sigma_{\mathrm{f}}^{\mathrm{u}} V_{\mathrm{f}}
$$

where $\sigma_{\mathrm{fc}}^{\mathrm{u}}$ is the tensile strength of the complex and $\sigma_{\mathrm{f}}^{\mathrm{u}}$ is the tensile strength of the fibers. In [32-34], it was assumed that discontinuous fibers are uniformly distributed in the matrix material. By considering the influence of fiber orientation, length, and bonding between fibers and matrix material on the tensile strength of the complex, the effective coefficient of fiber, $\eta_{\mathrm{f}}$, is introduced, so the tensile strength is given by

$$
\sigma_{\mathrm{fc}}^{\mathrm{u}}=\eta_{\mathrm{f}} \sigma_{\mathrm{f}}^{\mathrm{u}} V_{\mathrm{f}}=\eta_{\mathrm{l}} \eta_{\theta} \eta_{\mathrm{b}} \sigma_{\mathrm{f}}^{\mathrm{u}} V_{\mathrm{f}},
$$

where $\eta_{1}$ is the fiber length coefficient, $\eta_{\mathrm{b}}$ is the bond coefficient of fibers and matrix material, and $\eta_{\theta}$ is the orientation coefficient of fibers in the matrix material. Given the existence of fiber clustering, fiber composites contain clustering fibers and uniformly distributed fibers. Therefore, the ratio of volume fraction $\left(V_{\mathrm{fe}}\right)$ of clustering fibers to the total volume fraction $\left(V_{\mathrm{f}}\right)$ of fibers is defined as the clustering fiber content $w$ :

$$
w=\frac{V_{\mathrm{fe}}}{V_{\mathrm{f}}} \times 100 \% .
$$

According to (2) and (13), the tensile strength of the $\mathrm{BF} / \mathrm{EP}$ composite material with fiber clustering taken into account is

$$
\begin{aligned}
\sigma_{\mathrm{fc}}^{\mathrm{u}}= & \eta_{\mathrm{f}} \sigma_{\mathrm{f}}^{\mathrm{u}} V_{\mathrm{f}}=\eta_{\mathrm{f}} \sigma_{\mathrm{f}}^{\mathrm{u}}\left(1-V_{\mathrm{fe}}\right)+\eta_{\mathrm{f}} \eta_{\mathrm{e}} \sigma_{\mathrm{f}}^{\mathrm{u}} V_{\mathrm{fe}} \\
= & \eta_{\mathrm{f}} \sigma_{\mathrm{f}}^{\mathrm{u}} V_{\mathrm{f}}\left(1-w+\eta_{\mathrm{e}} w\right) .
\end{aligned}
$$

Representative sections of $\mathrm{BF} / \mathrm{EP}$ composite material samples with the volume fractions of $0.6 \%, 0.9 \%, 1.2 \%$, and $1.5 \%$ were magnified for observation after cutting and polishing so that the number of clustering fibers and inside arrangement can be obtained, as shown in Figure 8(a) (an agglomerate of fibers). The arrangement pattern of fiber agglomerates in Figure 8(a) was cut, with the cutting line of fiber agglomerates and matrix material being a solid polygon, as shown in Figure 8(b). All edges of the solid polygon are offset inward by $d_{\mathrm{f}} / 2$ to form a dotted polygon, which is a polygon formed from the fiber center in the periphery of this agglomerate of fibers. We calculated the area $S$ of the solid polygon and perimeter $c$ of the dotted polygon. Table 3 lists $c_{j}$ and $S_{j}$ values for the $j$ th fiber agglomerate in the representative section of the $\mathrm{BF} / \mathrm{EP}$ sample for different volume fractions of basalt fiber.

By taking a section from the oriented basalt fiber/epoxy composite material samples with different volume fractions $(0.6 \%, 0.9 \%, 1.2 \%$, and $1.5 \%)$, the length of each being $12 \mathrm{~mm}$, as a representative volume unit, the effective coefficient of fiber $\left(\eta_{\mathrm{f}}\right)$ was calculated according to the method in [32-34] and $\mu$ is 0.33 [35]. We then calculated the equidistribution coefficients of all fiber agglomerates in the representative volume unit using (14) and took the average value of these coefficients as the equidistribution coefficient of fiber in this representative volume unit. The clustering fiber content of the representative volume unit was calculated according to (18). Figure 9 shows the fiber equidistribution coefficient $\eta_{\mathrm{e}}$ and clustering fiber content $w$ of different fiber volume fractions. As shown in Figure 9, with the increase of fiber volume fraction, the fiber equidistribution coefficient decreases and the fiber clustering content increases.

By substituting the fiber equidistribution coefficient $\eta_{\mathrm{e}}$ under different fiber volume fractions and clustering fiber 

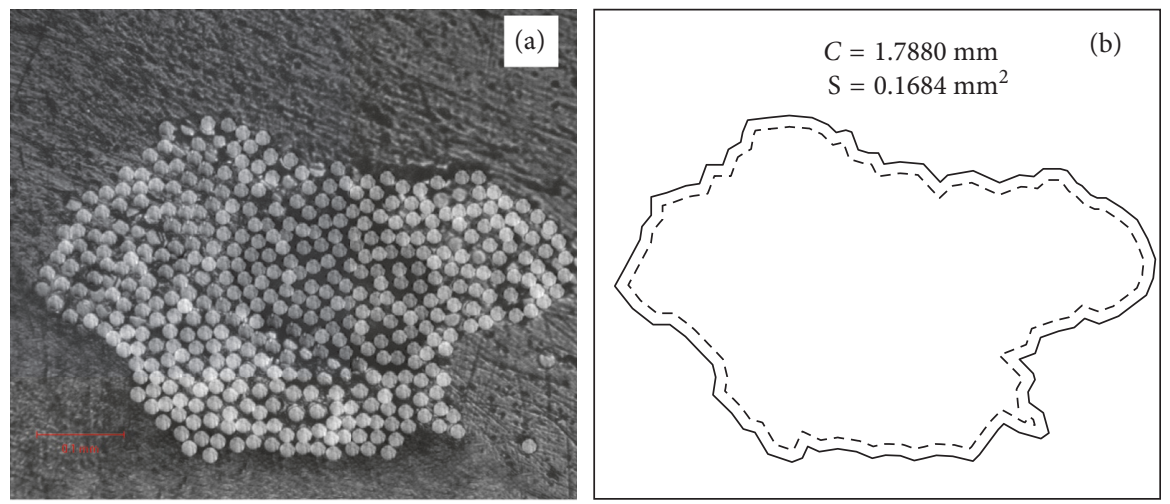

Figure 8: Graph division and calculation of $C$ and $S$ for a cluster fiber.

TABLE 3: Calculated values of $c$ and $S$ for the $j$ th fiber clustering with different fiber volume fractions.

\begin{tabular}{|c|c|c|c|c|c|c|c|c|}
\hline \multirow[b]{2}{*}{$j$} & \multicolumn{2}{|c|}{$i=0.6 \%$} & \multicolumn{2}{|c|}{$i=0.9 \%$} & \multicolumn{2}{|c|}{$i=1.2 \%$} & \multicolumn{2}{|c|}{$i=1.5 \%$} \\
\hline & $c_{j}(\mathrm{~mm})$ & $S_{j}\left(\mathrm{~mm}^{2}\right)$ & $c_{j}(\mathrm{~mm})$ & $S_{j}\left(\mathrm{~mm}^{2}\right)$ & $c_{j}(\mathrm{~mm})$ & $S_{j}\left(\mathrm{~mm}^{2}\right)$ & $c_{j}(\mathrm{~mm})$ & $S_{j}\left(\mathrm{~mm}^{2}\right)$ \\
\hline 1 & 1.6873 & 0.1297 & 2.2260 & 0.2516 & 1.7707 & 0.1216 & 1.9107 & 0.1247 \\
\hline 2 & 2.1040 & 0.2116 & 2.0927 & 0.1159 & 1.4033 & 0.0869 & 1.3867 & 0.0752 \\
\hline 3 & 1.0007 & 0.0566 & 1.5520 & 0.0903 & 1.8380 & 0.1683 & 1.3893 & 0.1380 \\
\hline 4 & 0.8187 & 0.0493 & 1.6253 & 0.0956 & 1.1933 & 0.0966 & 1.5607 & 0.1260 \\
\hline 5 & 1.6520 & 0.0930 & 1.7587 & 0.1676 & 1.3293 & 0.0992 & 1.6360 & 0.1342 \\
\hline 6 & 1.7920 & 0.1739 & 1.7880 & 0.1684 & 1.4427 & 0.1413 & 1.3000 & 0.1041 \\
\hline 7 & - & - & 1.6073 & 0.1047 & 1.6980 & 0.1489 & 1.5373 & 0.1346 \\
\hline 8 & - & - & 1.6093 & 0.0887 & 1.4333 & 0.1111 & 1.4927 & 0.1354 \\
\hline 9 & - & - & 1.3620 & 0.0674 & 1.4267 & 0.1195 & 1.4587 & 0.1337 \\
\hline 10 & - & - & - & - & 1.1420 & 0.0857 & 1.2833 & 0.0870 \\
\hline 11 & - & - & - & - & 1.5180 & 0.1199 & 1.4673 & 0.1136 \\
\hline 12 & - & - & - & - & 1.5467 & 0.1460 & 1.3733 & 0.1151 \\
\hline 13 & - & - & - & - & 1.5067 & 0.1380 & 1.6620 & 0.1601 \\
\hline 14 & - & - & - & - & - & - & 1.2527 & 0.0982 \\
\hline 15 & - & - & - & - & - & - & 1.3993 & 0.1104 \\
\hline 16 & - & - & - & - & - & - & 1.3820 & 0.1068 \\
\hline 17 & - & - & - & - & - & - & 1.4807 & 0.1082 \\
\hline 18 & - & - & - & - & - & - & 1.8280 & 0.1551 \\
\hline 19 & - & - & - & - & - & - & 1.6640 & 0.1220 \\
\hline
\end{tabular}

contents $w$ into (16), we obtained the BF/EP composite material tensile strength calculated values with fiber clustering effect taken into account. Figure 10 shows the BF/EP composite material tensile strength calculated values of equidistributed fibers (without consideration of fiber clustering effect: $w=0$ ), the BF/EP composite material tensile strength calculated values with fiber clustering effect taken into account, and the $\mathrm{BF} / \mathrm{EP}$ composite material tensile strength test values of different fiber volume fractions.

From Figure 10, one can see that the calculated values for $\mathrm{BF} / \mathrm{EP}$ composite material tensile strength without fiber clustering effect taken into account (i.e., fibers are distributed uniformly), the calculated values of the BF/EP composite material tensile strength values with fiber clustering effect taken into account, and the BF/EP composite material tensile strength values obtained by testing all increase as the fiber volume fraction increases. When the fiber volume fraction is constant, the calculated value of the BF/EP composite material tensile strength without consideration of fiber clustering (i.e., if fibers are distributed uniformly) is higher than the test value and has a larger deviation. Other research [36] has shown that when the fibers are distributed uniformly, the complex strength value predicted by Tsai theory deviates significantly from the test value. However, when the fiber volume fraction is constant, the BF/EP composite material tensile strength calculated value with fiber clustering effect taken into account is lower than that of equidistributed fibers and is closer to the test value. The results of a linear regression between the calculated values of $\mathrm{BF} / \mathrm{EP}$ composite material tensile strength with consideration of fiber clustering effect and the test values are as follows:

$$
\begin{aligned}
\sigma_{y} & =1.01 \sigma_{x}+1.44, \\
R^{2} & =0.991
\end{aligned}
$$

where $\sigma_{y}$ is the $\mathrm{BF} / \mathrm{EP}$ composite material tensile strength value obtained by testing and $\sigma_{x}$ is the calculated value of the 


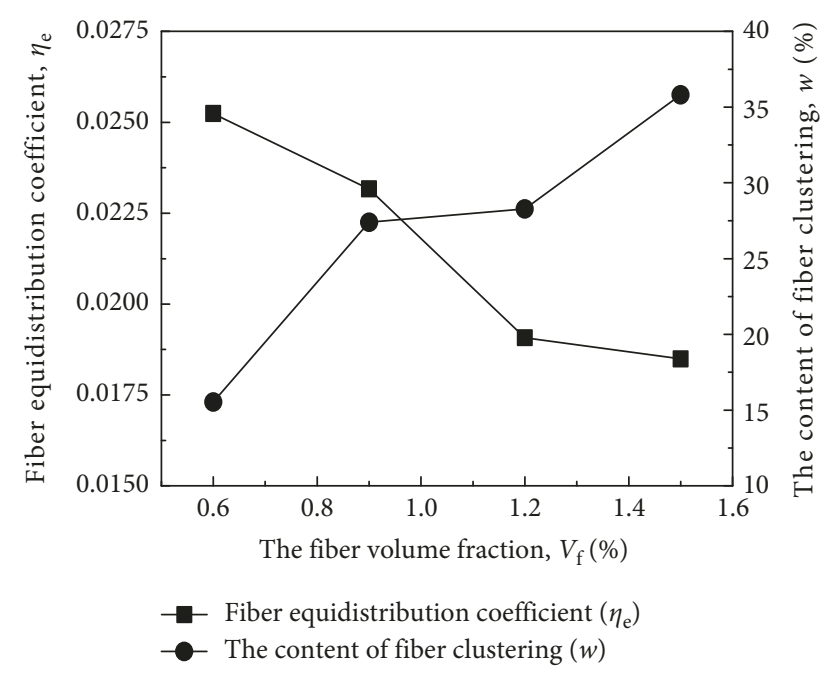

Figure 9: Fiber equidistribution coefficient and content of fiber clustering as a function of fiber volume fraction.

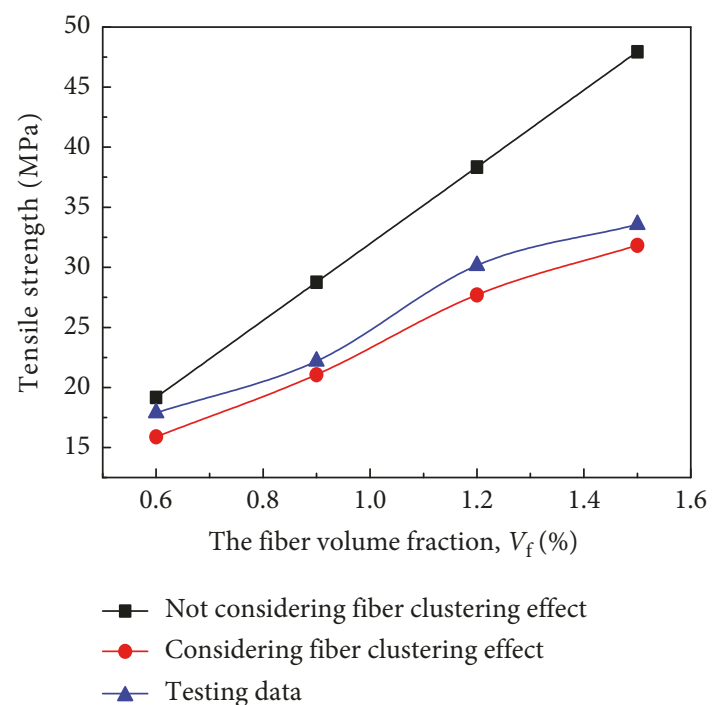

Figure 10: Calculated and experimental values of the tensile strength of the $\mathrm{BF} / \mathrm{EP}$ composite material as a function of fiber volume fraction change.

$\mathrm{BF} / \mathrm{EP}$ composite material tensile strength with consideration of fiber clustering effect. The correlation coefficient is $>0.991$, which indicates a strong linear correlation. This conclusion can provide a theoretical basis and reference value for predicting the tensile strength of $\mathrm{BF} / \mathrm{EP}$ composite material.

\section{Conclusion}

Different fiber orientations and BF/EP composite material tensile strength experiments were analyzed, and research on failure modes of different fiber volume fractions was conducted. The following can be concluded:

(1) With a certain amount of basalt fiber, the tensile strength, elastic modulus, and limiting strain of epoxy resin composite material significantly improve. When the fiber volume fraction is constant, the tensile strength, elastic modulus, and limiting strain of BF/EP composite material all decrease with increasing fiber orientation angle. When the fiber orientation angle is constant, the tensile strength, elastic modulus, and limiting strain of BF/EP composite material all increase with increasing fiber volume fraction.

(2) The fibers play an enhanced role in the matrix when the bonding strength of the fiber and matrix is greater than the yield strength of the fiber. However, the matrix is destroyed before the pullout fiber reaches its yield limit, and the bonding strength of the fiber and matrix is smaller than the tensile strength of the fiber, so the fibers do not play an enhanced role in the matrix.

(3) The calculated values of the BF/EP composite material tensile strength with fiber clustering effect taken into account and the test values exhibit a strong linear correlation (with a correlation coefficient of 0.991). This conclusion can provide a theoretical basis and reference value for predicting the tensile strength of $\mathrm{BF} / \mathrm{EP}$ composite material.

\section{Data Availability}

The data used to support the findings of this study are available from the corresponding author upon request.

\section{Disclosure}

This work was presented in the form of abstract in "The 8th International Conference on Computational Methods (ICCM2017).”

\section{Conflicts of Interest}

The authors declare that they have no conflicts of interest.

\section{Acknowledgments}

The authors would like to thank the opportunity offered by the ICCM2017 on the exchange of "tensile mechanical properties and its failure modes of the basalt fiber/epoxy resin composite material." The authors gratefully acknowledge the support of the National Natural Science Foundation of China (no. 11572244) and NSAF (no. U1630144).

\section{References}

[1] C. Colombo, L. Vergani, and M. Burman, "Static and fatigue characterisation of new basalt fibre reinforced composites," Composite Structure, vol. 94, no. 4, pp. 1165-1174, 2012.

[2] V. Fiore, G. D. Bella, and A. Valenza, "Glass-basalt/epoxy hybrid composites for marine applications," Materials \& Design, vol. 32, no. 4, pp. 2091-2099, 2010.

[3] B. Wei, H. Cao, and S. Song, "Tensile behavior contrast of basalt and glass fibers after chemical treatment," Materials \& Design, vol. 31, no. 9, pp. 4244-4250, 2010. 
[4] V. Lopresto, C. Leone, and I. D. Iorio, "Mechanical characterisation of basalt fibre reinforced plastic," Composites Part B Engineering, vol. 42, no. 4, pp. 717-723, 2011.

[5] A. Todic, B. Nedeljkovic, D. Cikara, and I. Ristovic, "Particulate basalt-polymer composites characteristics investigation," Materials \& Design, vol. 42, no. 4, pp. 1677-1683, 2011.

[6] M. T. Kim, M. H. Kim, K. Y. Rhee, and S. J. Park, "Study on an oxygen plasma treatment of a basalt fiber and its effect on the interlaminar fracture property of basalt/epoxy woven composites," Composites Part B Engineering, vol. 42, no. 3, pp. 499-504, 2011.

[7] M. F. M. Fahmy, Z. Wu, G. Wu, and Z. Sun, "Post-yield stiffnesses and residual deformations of RC bridge columns reinforced with ordinary rebars and steel fiber composite bars," Engineering Structures, vol. 32, no. 9, pp. 2969-2983, 2010.

[8] G. M. Chen, S. W. Li, D. Fernando, P. C. Liu, and F. J. Chen, "Full-range FRP failure behaviour in RC beams shearstrengthened with FRP wraps," International Journal of Solids and Structures, vol. 125, no. 15, pp. 1-21, 2017.

[9] A. Godat, Z. Qu, X. Z. Lu, P. Labossière, L. P. Ye, and K. W. Neale, "Size effects for reinforced concrete beams strengthened in shear with CFRP strips," Journal of Composites for Construction, vol. 14, no. 3, pp. 260-271, 2010.

[10] Y. S. Shin, "Flexural behavior of reinforced concrete beams strengthened with carbon fiber-reinforced polymer laminates at different levels of sustaining load," ACI Structural Journal, vol. 100, no. 2, pp. 231-239, 2003.

[11] M. C. Sundarraja and S. Rajamohan, "Strengthening of RC beams in shear using GFRP inclined strips-an experimental study," Construction and Building Materials, vol. 23, no. 2, pp. 856-864, 2009.

[12] C. Pellegrino and C. Modena, "Fiber reinforced polymer shear strengthening of reinforced concrete beams with transverse steel reinforcement," Journal of Composites for Construction, vol. 6, no. 2, pp. 104-111, 2002.

[13] T. El-Amoury and A. Ghobarah, "Seismic rehabilitation of beam-column joint using GFRP sheets," Engineering Structures, vol. 7, no. 4, pp. 1397-1407, 2002.

[14] Y. Xiao, "Applications of FRP composites in concrete columns," Advances in Structural Engineering, vol. 7, no. 4, pp. 335-343, 2009.

[15] Y. C. Wang, M. G. Lee, and B. C. Chen, "Experimental study of FRP-strengthened RC bridge girders subjected to fatigue loading," Composite Structures, vol. 81, no. 4, pp. 491-498, 2007.

[16] J. H. Lee, K. Y. Rhee, and S. J. Park, “The tensile and thermal properties of modified CNT-reinforced basalt/epoxy composites," Materials Science and Engineering A, vol. 81, no. 4, pp. 6838-6843, 2010.

[17] N. Huonnic, M. Abdelghani, P. Mertiny, and A. Mcdonald, "Deposition and characterization of flame-sprayed aluminum on cured glass and basalt fiber-reinforced epoxy tubes," Surface and Coatings Technology, vol. 205, no. 3, pp. 867-873, 2010.

[18] A. J. Fletcher and J. L. Oakeshott, "Thermal residual micro stress generation during the processing of unidirectional carbon fibre/epoxy resin composites: random fibre arrays," Composites, vol. 25, no. 8, pp. 806-813, 1994.

[19] T. Hobbiebrunken, M. Hojo, K. K. Jin, and S. K. Ha, "Influence of non-uniform fiber arrangement on microscopic stress and failure initiation in thermally and transversely loaded CF/epoxy laminated composites," Composites Science and Technology, vol. 68, no. 15, pp. 3107-3113, 2008.
[20] C. Yang, H. X. Huang, and K. Li, "Investigation of fiber orientation states in injection-compression molded shortfiber-reinforced thermoplastics," Polymer Composites, vol. 31, no. 11, pp. 1899-1908, 2010.

[21] K. Pochiraju and V. Jovanović, "Modeling material property heterogeneity in fiber-reinforced injection molded plastic parts," Polymer Composites, vol. 26, no. 1, pp. 98-113, 2005.

[22] L. L. Gui, H. W. Zhou, and H. W. Wang, "Theoretical analysis of young's modulus for unidirectional fiber reinforced composites with different fiber orientations," Advanced Materials Research, vol. 216, pp. 773-776, 2011.

[23] B. X. Yang, J. Y. Ou, W. Zhou, F. Wang, and X. J. Li, "Dynamic simulation of fiber orientation in the gap flow field between two rotating cylinders," Acta Physica Sinica, vol. 64, no. 11, pp. 404-413, 2015.

[24] H. Zhang and O. Jie, "Fiber orientation and stress analysis for fiber reinforced polymeric melt," Acta Materiae Compositae Sinica, vol. 24, no. 6, pp. 153-159, 2007.

[25] Z. Ye, D. Lee, S. A. Campbell, and T. Cui, "Thermally enhanced single-walled carbon nanotube microfluidic alignment," Microelectronic Engineering, vol. 88, no. 9, pp. 2919-2923, 2011.

[26] V. C. S. Chandrasekaran, S. G. Advani, and M. H. Santare, "Role of processing on interlaminar shear strength enhancement of epoxy/glass fiber/multi-walled carbon nanotube hybrid composites," Carbon, vol. 48, no. 13, pp. 3692-3699, 2010.

[27] J. J. He, J. P. Shi, X. S. Cao, and T. L. Han, "Tensile mechanical properties and its failure modes of the basalt fiber/ epoxy resin composite material," in Proceedings of the 8th International Conference on Computational Methods (ICCM 2017) Article ID 2778, Guilin, China, July 2017.

[28] S. W. Tsai and E. M. Wu, "A general theory of strength for anisotropic materials," Journal of Composite Materials, vol. 5, no. 1 , pp. 58-80, 1971.

[29] K. S. Liu and S. W. Tsai, "A progressive quadratic failure criterion for a laminate 1," Composites Science and Technology, vol. 58, no. 7, pp. 1023-1032, 1998.

[30] V. I. Trefilov, V. V. Kartuzov, and N. V. Minakov, "Fractal dimension of fracture surfaces," Metal Science and Heat Treatment, vol. 43, no. 3, pp. 95-98, 2001.

[31] Y. Li, Q. Yan, and X. Du, "Relationship between autogenous shrinkage and tensile strength of cement paste with SCM," Journal of Materials in Civil Engineering, vol. 24, no. 19, pp. 1268-1273, 2012.

[32] P. Soroushian and C. D. Lee, "Distribution and orientation of fibers in steel fiber reinforced concrete," ACI Materials Journal, vol. 87, no. 5, pp. 433-439, 1990.

[33] D. Dupont and L. Vandewalle, "Distribution of steel fibres in rectangular sections," Cement and Concrete Composites, vol. 27, no. 3, pp. 391-398, 2005.

[34] S.Y. Fu and B. Lauke, "Effects of fiber length and fiber orientation distributions on the tensile strength of short-fiberreinforced polymers," Composites Science and Technology, vol. 56, no. 10, pp. 1179-1190, 1996.

[35] L. Zou, X. Li, W. G. Sun, P. G. Li, and Q. Q. Zhang, "Performance evaluation of basalt filament," Journal of Xi'an Polytechnic University, vol. 27, no. 3, pp. 314-318, 2013.

[36] Y. Swolfs, L. Gorbatikh, and I. Verpoest, "Fibre hybridisation in polymer composites: a review," Composites Part A Applied Science and Manufacturing, vol. 67, no. 12, pp. 181-200, 2014. 


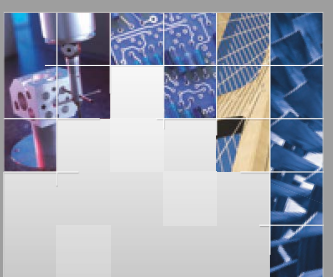

\section{Enfincering}
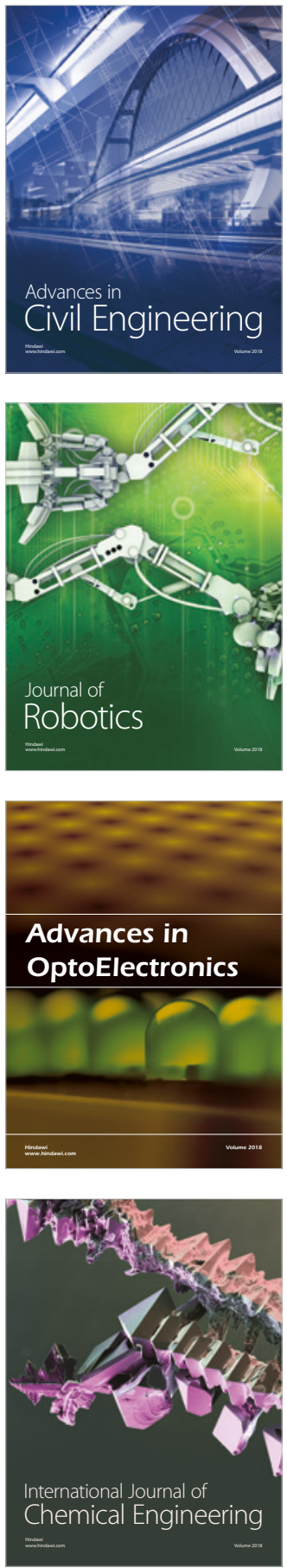

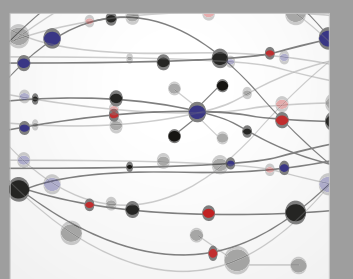

\section{Rotating \\ Machinery}

The Scientific World Journal

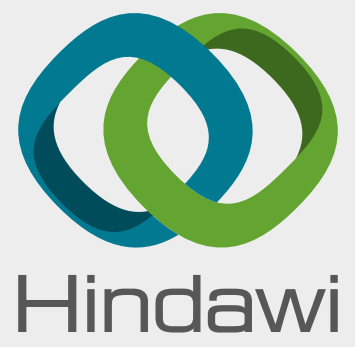

Submit your manuscripts at

www.hindawi.com
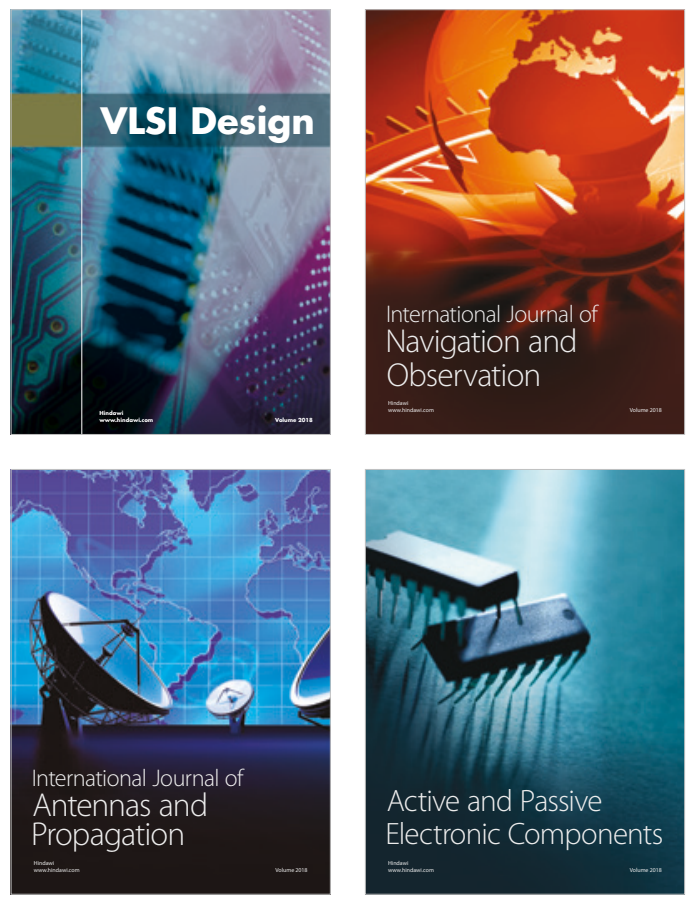
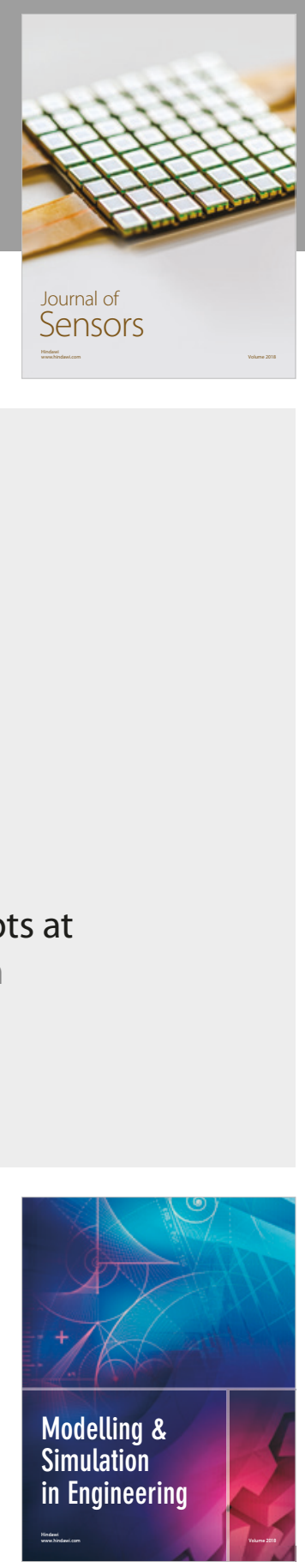

\section{Advances \\ Multimedia}
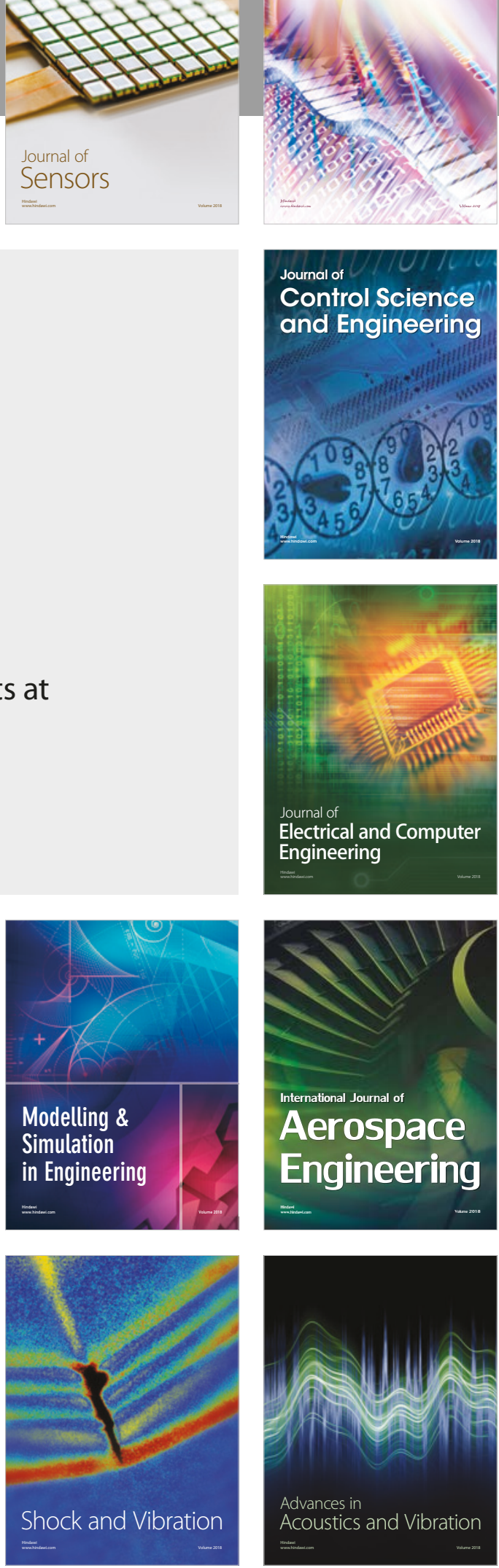